\title{
Distributed power electronics for PV systems
}

\section{National Renewable Energy Laboratory's EPRI PV Technology Seminar}

\author{
Chris Deline
}

$12 / 15 / 2011$

NREL/PR-5200-54183 


\section{Overview}

- Introduction to PV power electronics

- Types of mismatch in PV systems

- Performance improvement from distributed electronics

- Market share and other considerations 


\section{Introduction - Distributed power electronics}

- Per-module electronics (DC-DC,

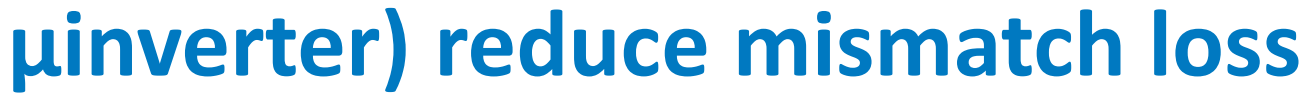

- Each device tracks individual module max power point.

- Decouples the panel voltage \& current from the rest of the string

- Monitoring capability

- Safety, anti-theft
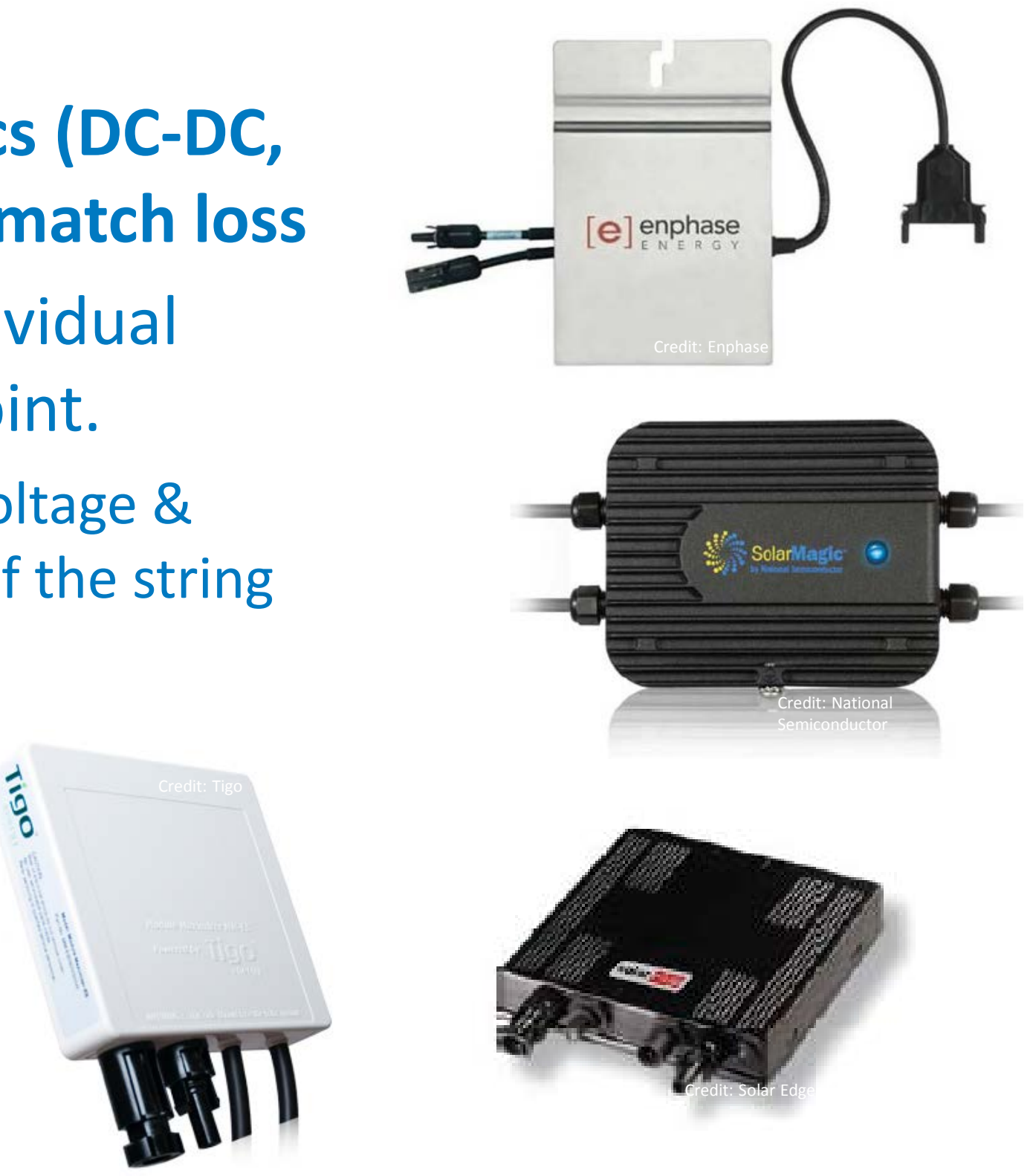


\section{How DC-DC converters work}

The output of a DC-DC converter is a constant power curve with voltage and current upper limits.

Impaired modules have their current boosted to match $I_{m p}$ of unshaded modules.

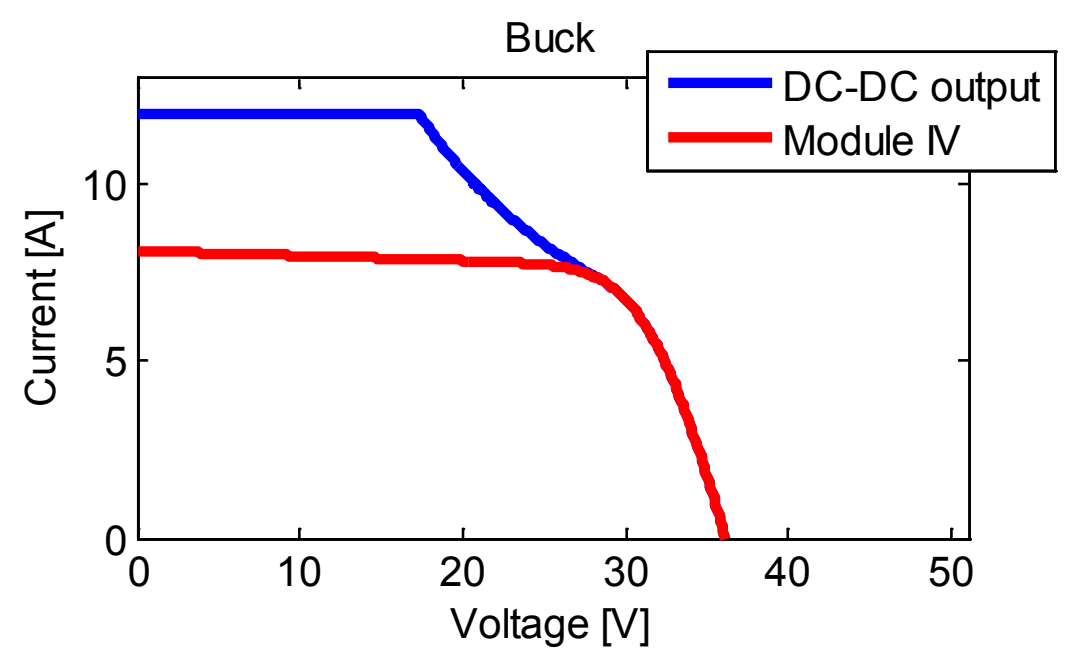

With buck-boost devices, voltage of unshaded modules can be boosted to match parallel string voltage.

Note that device efficiency and insertion loss may offset gains

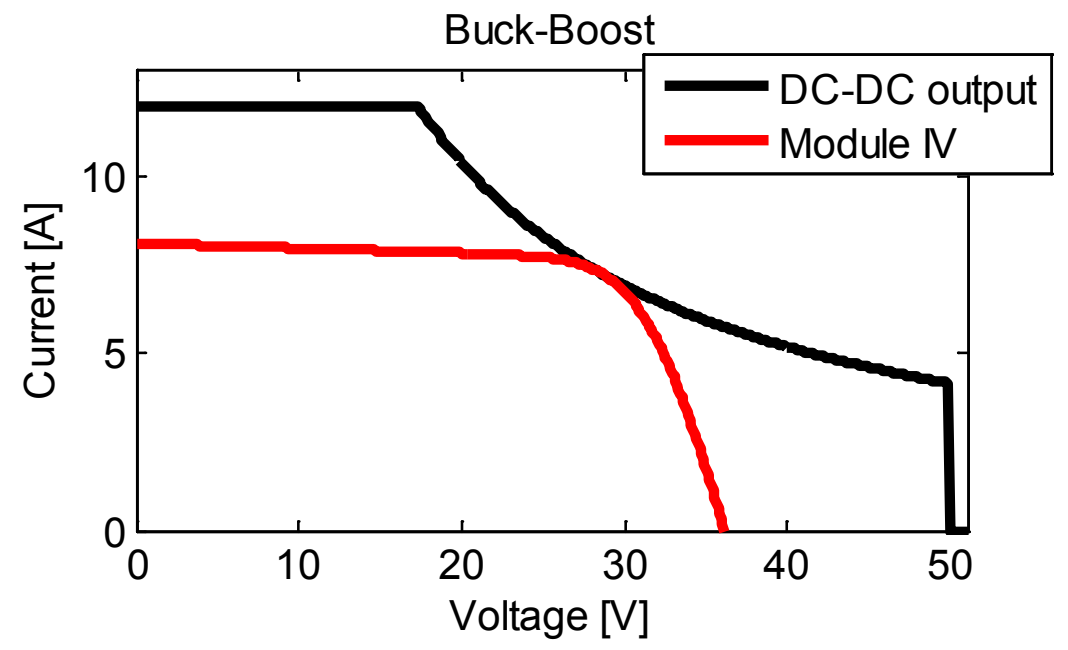




\section{Introduction - Impact of Shade}

- Shade impact depends on module type (fill factor, bypass diode placement), severity of shade, and string configuration.

- Power loss occurs from shade, also current mismatch within a PV string and voltage mismatch between parallel strings.

- Power lost is greater than proportional to the amount of shade on the system

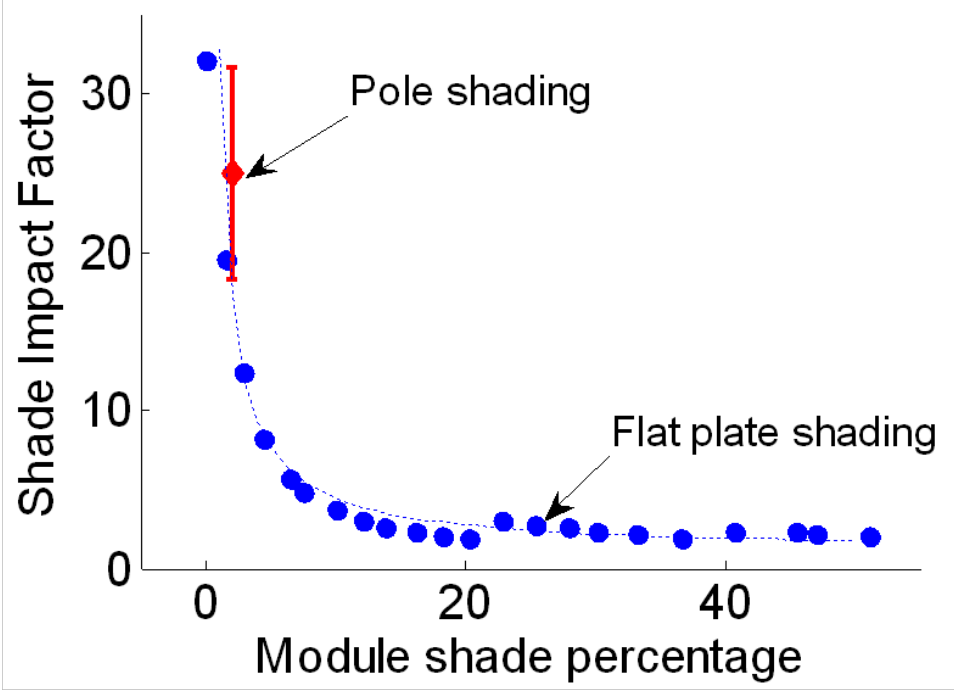

'Shade Impact Factor' (ratio of power lost to area of shade) for a single module in a single string $P V$ system ${ }^{[1]}$

[1] C. Deline, IEEE PVSC, 2009 


\section{Introduction - Other sources of mismatch}

Other types of mismatch can impact system performance:

- Soiling (dirt accumulation, bird droppings, snow build-up)

- Orientation of panels on different roof planes

- Distribution of panels' Imp rating (manufacturers typically bin to $2 \%$ )

- Differential aging

- Inverter voltage limits

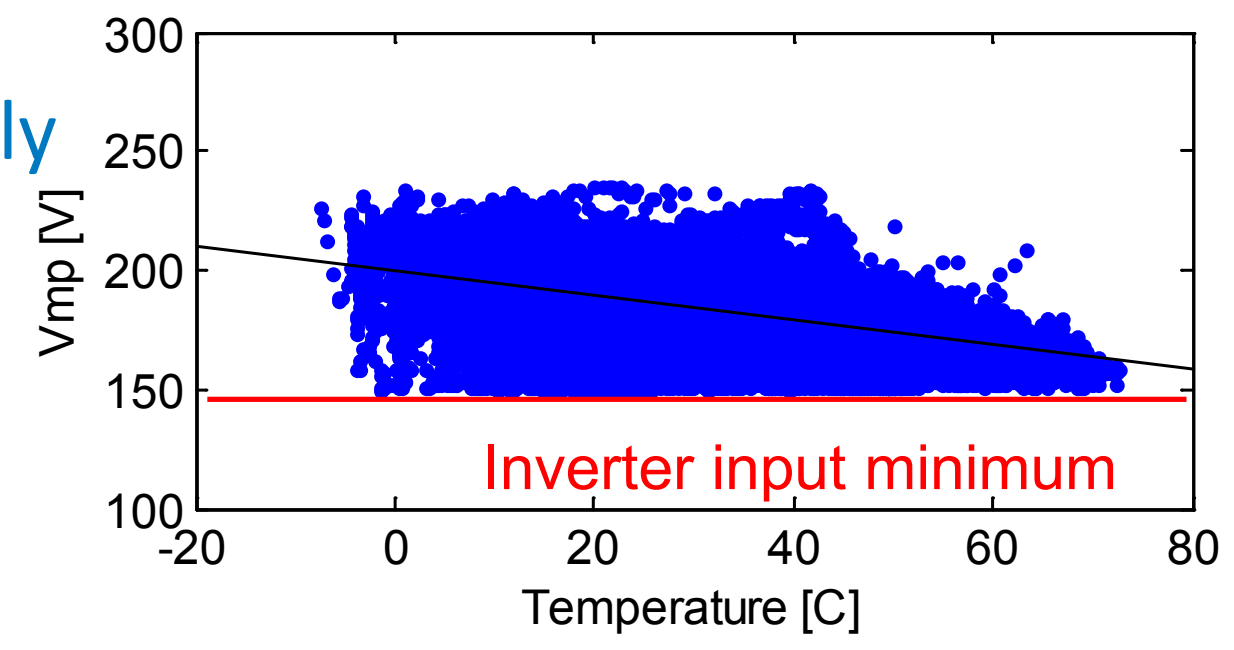

Inverter Vmp clipping due to high temperature and partial shade 


\section{Example mismatch losses}

\begin{tabular}{|l|c|c|l|}
\hline Type of mismatch & System loss (est) & Potential DC-DC gain* & Ref \\
\hline Residential roof shade, 1 string & $5-15 \%$ & $+15-20 \%$ of loss & {$[2]$} \\
\hline $\begin{array}{l}\text { Residential rooftop shade - } \\
\text { multiple strings }\end{array}$ & $5-20 \%$ & $+20-30 \%$ of loss & {$[2]$} \\
\hline $\begin{array}{l}\text { Commercial system with inter- } \\
\text { row shading }\end{array}$ & $1-5 \%$ & $+30-40 \%$ of loss & {$[3]$} \\
\hline $\begin{array}{l}\text { Residential orientation } \\
\text { mismatch, } 1 \text { string (East-West) }\end{array}$ & $5-20 \%$ & $+100 \%$ of loss & {$[4]$} \\
\hline $\begin{array}{l}\text { Imp distribution mismatch } \\
\text { Soiling - CA and Southwest US }\end{array}$ & $1.5-6.2 \%$ & $+15-40 \%$ of loss & {$[5]$} \\
\hline
\end{tabular}

${ }^{*}$ Not accounting for device efficiency or diode insertion loss

[2] C. Deline, IEEE PVSC, 2010

[3] C. Deline et al, NREL technical report TP5200-50003

[4] S. MacAlpine, ASME, ES2009

[5] A. Kimber, IEEE Conference on PV energy conversion, 2006 


\section{Estimates of performance improvement from PV power electronics}

Side by side comparison, $8 \mathrm{~kW}$ systems - one with micro-inverters, one with a string inverter [7]
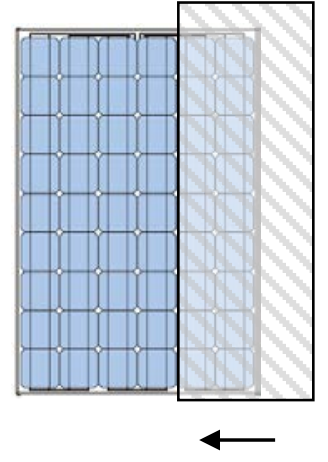

4\%-12\% performance improvement

[3] C. Deline et al, NREL technical report TP520050003

[6] S. MacAlpine, EUPVSEC, 4AV.3.15, 2011

[7] C. Deline et al, "Partial Shading Testbed for PVIntegrated Power Electronics Operating Procedure - Draft"
CAD shading simulation [6]

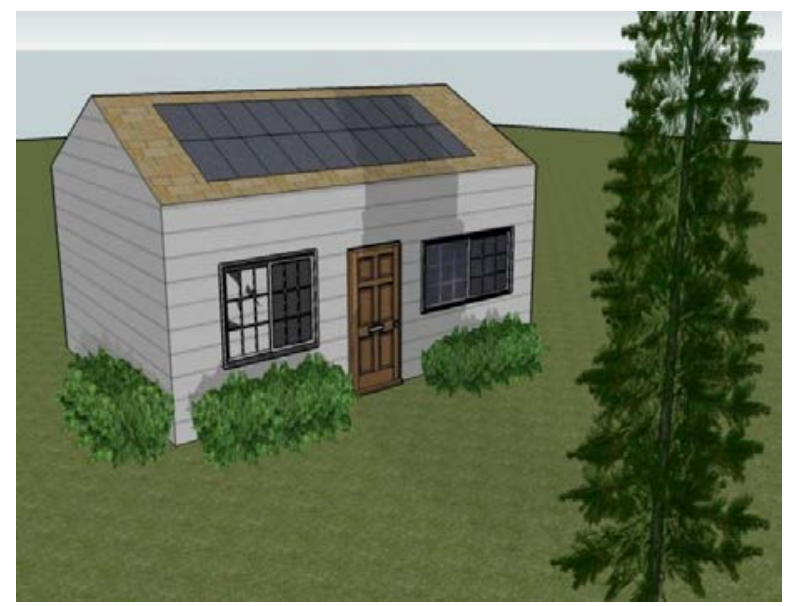

4\%-8\% performance improvement

Site survey based simulation [3]

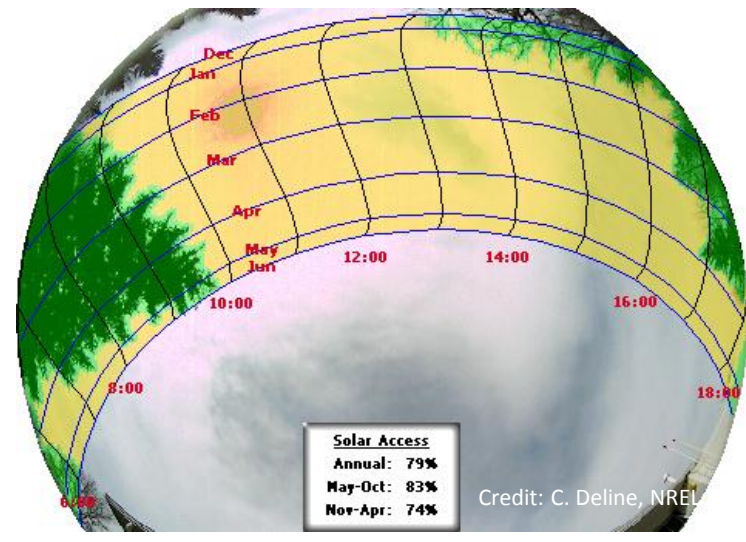

3\%-6\% performance improvement 


\section{Current market share of micros and DC-DC}

Majority of sales are for residential systems

- Tigo: $90 \%$ of sales are $<30 \mathrm{~kW}$ Business is good and growing:

- Enphase had $13 \%$ share of CA installations $<10 \mathrm{~kW}$ in 2010. [8]

- Market is growing $>100 \% / y r$ Lots of mismatched PV systems out there:

- Site survey shows $7.6 \%$

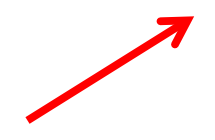
median shading, with a long tail.

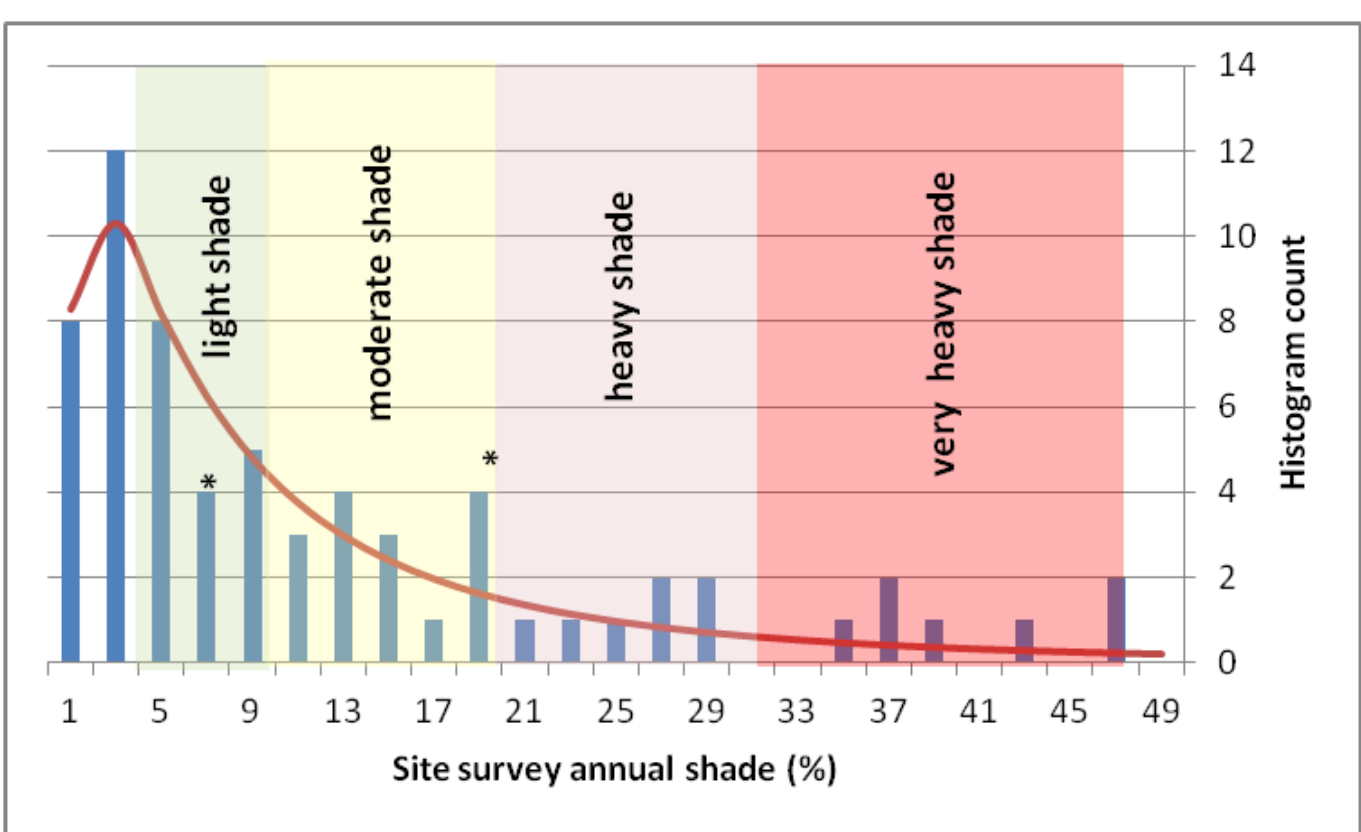

Residential site survey distribution showing 7.6\% median annual shading [Solar Works, CA]

[8] Enphase press release dated 1/19/11 based on CSI database for CA installations $<10 \mathrm{~kW}$ 


\section{Interesting future trends:}

- Enphase's efficiency already beats some string inverters (M-215 has $\eta_{C E C}=96 \%$ )

- Incremental cost to add DC power optimizers to a system will be $5-10$ c/W by $2012 .{ }^{1}$

- Distributed power electronics will account for $1 \mathrm{GW}$, or $5 \%$ of inverter capacity by $2013 .^{2}$

- $45 \%$ of units will be packaged directly into PV modules by $2015 .^{2}$

1: Tigo energy 2: IMS Research 


\section{Additional considerations:}

Added benefits to using per-panel devices may include:

- Per-module performance monitoring

- Emergency shut-off or lower voltage for fireman safety

- Ability to add more PV panels at a later date

- Greater freedom in design and layout

Some concerns to keep in mind may include:

- Different devices may not be inter-operable, obsolescence risk may be a concern.

- Insertion loss during unshaded times may offset benefit

- Additional equipment $=$ more points of failure 


\section{In conclusion...}

- The impact of shade is greater than just the area of shade

- Additional mismatch losses include panel orientation, panel distribution, inverter voltage window, soiling

- Per-module devices can help increase performance, 4$12 \%$ or more depending on the system.

- Value-added benefits (safety, monitoring, reduced design constraints) are helping their adoption

- The residential market is growing rapidly. Efficiency increases, cost reductions are improving market acceptance. Panel integration will further reduce price and installation cost. Reliability remains an unknown. 
